\title{
Double-hit lymphomas: clinical, morphological, immunohistochemical and cytogenetic study in a series of Brazilian patients with high-grade non-Hodgkin lymphoma
}

Cristiano Claudino Oliveira ${ }^{1,6^{*}}$, Helena Maciel-Guerra², Luan Kucko ${ }^{2}$, Eric Jun Hirama², Américo Delgado Brilhante ${ }^{3}$, Francisco Carlos Quevedo ${ }^{4}$, Isabela Werneck da Cunha ${ }^{3}$, Fernando Augusto Soares ${ }^{3}$, Ligia Niero-Melo ${ }^{5}$,

Patrícia Pintor dos Reis ${ }^{2}$ and Maria Aparecida Custodio Domingues ${ }^{1}$

\begin{abstract}
Background: Double-hit lymphomas $(\mathrm{DHL})$ are rare high-grade neoplasms characterized by two translocations: one involving the gene MYC and another involving genes $B C L 2$ or $B C L 6$, whose diagnosis depends on cytogenetic examination. This research studied DHL and morphological and/or immunophenotypic factors associated with the detection of these translocations in a group of high-grade non-Hodgkin lymphoma cases.

Method: Clinical and morphological reviews of 120 cases diagnosed with diffuse large B-cell lymphoma and Burkitt lymphoma were conducted. Immunohistochemistry (CD20, CD79a, PAX5, CD10, Bcl6, Bcl2, MUM1, TDT and Myc) and fluorescence in situ hybridization for detection of $M Y C, B C L 2$ and $B C L 6$ gene translocations were performed in a tissue microarray platform.
\end{abstract}

Results: Three cases of DHL were detected: two with translocations of MYC and BCL2 and one with translocations of MYC and BCL6, all leading to death in less than six months. Among 90 cytogenetically evaluable biopsies, associations were determined between immunohistochemistry and fluorescence in situ hybridization for MYC $(p=0.036)$ and $B C L 2$ $(p=0.001)$. However, these showed only regular agreement, indicated by Kappa values of $0.23[0.0 ; 0.49]$ and 0.35 [0.13; $0.56]$, respectively. "Starry sky" morphology was strongly associated with MYC positivity $(p=0.01)$. The detection of three cases of DHL, all resulting in death, confirms the rarity and aggressiveness of this neoplasm.

Conclusions: The "starry sky" morphological pattern and immunohistochemical expression of Myc and Bcl2 represent possible selection factors for additional cytogenetic diagnostic testing.

Keywords: Lymphoma, Lymphoma, non-Hodgkin, Cytogenetics, In situ hybridization fluorescence, Immunohistochemistry

\footnotetext{
* Correspondence: cristiano_c_oliveira@hotmail.com

${ }^{1}$ Department of Pathology, Botucatu School of Medicine, São Paulo State

University (FMB UNESP), Botucatu, São Paulo, Brazil

${ }^{6}$ Departamento de Patologia, Faculdade de Medicina de Botucatu (FMB),

Universidade Estadual Paulista (UNESP), Distrito de Rubião Junior, s/nº,

Botucatu, SP Zip code: 18618-000, Brazil

Full list of author information is available at the end of the article
} 


\section{Background}

Double-hit lymphomas (DHL) are aggressive neoplasms presenting translocation phenomenon involving the $M Y C$ gene combined with another event involving translocation of the BCL2 or BCL6 gene [1-6]. The combination of $M Y C$ translocation with translocations of BCL2 and BCL6 can also occur, defining the triple-hit lymphomas (THL) [1, 4, 7-9]. A diagnosis of DHL is only determined following the results of a cytogenetic test, such as fluorescence in situ hybridization (FISH) [10-12]. It represents approximately $15 \%$ of the provisional entity called Bcell lymphoma unclassifiable, with features intermediate between diffuse large B-cell lymphoma and Burkitt lymphoma (B-CLU/DLBCL/LB), Classification of Tumors of Haematopoietic and Lymphoid Tissues of the World Health Organization (WHO) in 2008 [1-4].

In 2016, Swerdlow et al. [13] published a proposal of revision in the WHO classification of 2008. This group of authors recognized DHL and THL as clinical and pathological categories, designated highgrade B-cell lymphomas (HGBL) with $M Y C$ and $B C L 2$ and/or BCL6 rearrangements. Cases with morphological aspects of HGBL without $M Y C$ and $B C L 2$ and/or $B C L 6$ rearrangements were placed in the HGBL, NOS. However, there is not a specific guideline to select which cases should have FISH studies [13]. The morphological and/or immunophenotypic parameters do not seem to effectively predict the detection of cytogenetic translocations involving $M Y C$, $B C L 2$ and BCL6 [4, 14]. Molecular cytogenetics, like $\mathrm{FISH}$, is not a readily available technique, mainly due to its high costs. Thus, determining which group of patients must have their biopsies submitted for this kind of test is a subject of controversy [4, 14, 15]. Despite the difficulties in interpreting the immunohistochemical profiles of $\mathrm{Myc}, \mathrm{Bcl} 2$ and $\mathrm{Bcl} 6$, several studies have been published on how this technique can be used as a method of screening for molecular research, since it is being incorporated into the clinical routine as this cytogenetic information becomes increasingly relevant in therapeutic practice and prognosis [16, 17].

This study identified cases of DHL in a series of high-grade non-Hodgkin lymphomas in Brazil, characterizing them according to their clinical, morphological, immunophenotypic and molecular features. In addition, the associations between the expression of $\mathrm{Myc}, \mathrm{Bcl} 2$ and $\mathrm{Bcl} 6$ proteins assessed by immunohistochemistry and the detection of translocations involving these genes were investigated in order to contribute to the discussions about how to select the cases of lymphoma for further molecular studies.

\section{Method}

\section{Patients and study design}

The authors selected 120 cases of patients with a pathological diagnosis of DLBCL or BL from two reference hospitals. Among the 120 cases selected following a review of pathology reports, 100 patients were diagnosed with DLBCL and 20 patients were diagnosed with LB. Patient records were reviewed from January 1998 to December 2013 at HC-FMB-UNESP, and from January 2010 to December 2011 at HAC. The study was approved by the Research Ethics Committee of FMBUNESP, under protocol no. 4385-2012.

Sociodemographic data and clinical information were reviewed, including infectious comorbidities, history of non-Hodgkin lymphoma (NHL), presence of B symptoms, nodal and/or extranodal involvement, central nervous system (CNS) involvement, bone marrow infiltration (MO), levels of lactic dehydrogenase (LDH), Ann-Arbor staging, adopted therapeutic management, clinical and evolutionary tracking and recurrences.

\section{Morphological features}

Hematoxylin and eosin (HE) slides of the 120 selected biopsies were evaluated according to the morphological criteria defined by the WHO, in its publication Classification of Tumours of Haematopoietic and Lymphoid Tissues, in 2008. The parameters adopted in this study were monomorphic/polymorphic cytological pattern, presence of "starry sky" pattern, diffuse growth, cytoplasmic eosinophilia, necrosis, mitotic activity, apoptosis, nuclear characteristics (vesicular, lobed, nucleolus, chromatin pattern), endothelial proliferation, stromal sclerosis and infiltration of adjacent soft tissues.

\section{Immunophenotypic evaluation, fluorescence in situ hybridization (FISH) and chromogenic in situ hybridization (CISH)}

For immunophenotypic and cytogenetic evaluation, a tissue microarray platform (TMA) was constructed using cores from selected areas of each biopsy of the 120 cases. The $1.0 \mathrm{~mm}$ diameter cores were duplicated, and spaced every $0.2 \mathrm{~mm}[18]$.

Immunohistochemical analysis was performed using the polymer detection system with staining with diaminobenzidine chromogen and counterstaining with hematoxylin. The markers used were: CD20 (clone L26, dilution 1: 250, Cell Marque), CD79a (clone JCB117, Dako, ready to use), PAX5 (DAK-PAX5 clone, ready to use, Dako), CD10 (clone 56C6, ready to use, Dako), Bcl6 (PGB6-P clone, ready to use, Dako), Bcl2 (clone 124, ready to use, Dako), MUM1 (clone MUM1P, ready to use, Dako), TDT (polyclonal, ready to use, Dako) and Myc (clone EP121, ready to use, Biocare). 
The expressions CD20, CD79a, PAX5, CD10, MUM1 and TDT were evaluated for positivity or negativity. The markers $\mathrm{Myc}, \mathrm{Bcl} 2$ and $\mathrm{Bcl} 6$ were assessed for percentage of cellular expression. For Myc and BCL6, biopsies were considered positive when the marker expression was greater than $50 \%$ of tumor cells. For Bcl2, the criterion of positivity used was $70 \%$ or more cells stained by the marker. Evaluation of cell proliferation by Ki67 (Clone MIB-1, ready to use; Dako) was stratified into less than $90 \%$, and equal to or greater than $90 \%$. The authors classified the DLBCL cases with the Hans algotithm, determining immunohistochemical patterns compatible with the germinal center profile type (GCB) and the non-germinal center profile type, also named $\mathrm{B}$ cells activated (ABC).

Fluorescence in situ hybridization (FISH) analysis was performed on the cores contained in the TMA block using probes specific for translocation detection involving the loci of the MYC (Vysis LSI MYC-IGH dual color, orange and green, break apart rearrangement probe; Abbott Molecular Des Plaines, IL, USA), BCL2 (Dako, $B C L 2$ FISH DNA, red and green, probe split signal) and $B C L 6$ genes (Vysis LSI, BCL6, dual color, orange and green, break apart probe rearrangement; Abbott Molecular Des Plaines, IL, USA), following the manufacturer's instructions. The FISH results were analyzed by fluorescence microscopy (BX61; Olympus, Center Valley, PA) with appropriate filters and the images were captured with a Q-Color 5 Olympus digital camera. A case was considered positive when $5.0 \%$ of the cells (at least 40 tumor cells were counted) of a sample showed separate orange/red and green signals [19].

Chromogenic in situ hybridization (CISH) for EBV (Epstein Barr Virus) was performed on the cores of TMA block using Vortex ZytoFast CISH probe, following the manufacturer's instructions. The CISH results were analyzed by optical microscopy, and each core was classified as positive or negative.

\section{Statistical analysis}

All analyzes were performed using SPSS, version 22.0. The analysis was descriptive, followed by the Chi square test and Fisher's exact test to compare proportions. The agreements between the immunohistochemical and FISH tests for the $M Y C, B C L 2$ and BCL6 markers were evaluated according to sensitivity, specificity, positive and negative predictive values, accuracy and Kappa coefficient, presented with their respective 95\% confidence intervals. The strength of the agreement determined by the Kappa coefficient was analyzed as follows: poor $(<0.20)$, regular $(0.21$ to 0.40$)$, moderate $(0.41$ to 0.60$)$, good $(0.61$ to 0,80$)$, very good ( 0.81 to 1.00$)$. The significance level ( $p$-value) tested was 0.05 .

\section{Results}

The 120 patients were submitted for clinical review, morphological analysis, immunohistochemistry and molecular evaluation. However, in 30 cases, flaws were verified in molecular testing in one or more of the three markers, related to issues of material fixation. FISH analysis detected three cases of DHL. The three groups defined by the cytogenetics investigation were BL $(n=15)$, DHL $(n=3)$ and DLBCL $(n=72)$; the sociodemographic, clinical, morphological, immunohistochemical and cytogenetic data are shown in Table 1.

\section{Clinical aspects}

Patients with BL were predominantly male (60\%), with a median age of four years old (range: 2-48 years old), and included one with HIV. These patients exhibited elevated LDH level (83.3\%), stage III/IV in clinical presentation (60\%), extranodal masses (83.3\%) and lymphadenopathy (53.3\%). Among patients with $\mathrm{BL}$, five patients (33.3\%) died, approximately 1.2 months after diagnosis $(\mathrm{SD}=0.83)$.

Among patients with DLBCL, males predominated (59.7\%) and the median age was 56.5 years old (range: 25-69 years old), with $47.2 \%$ of patients over 60 years old. Extranodal masses and enlarged lymph nodes were present in 49.3 and $61.9 \%$ of cases, respectively. Regarding treatment, 57 (79.2\%) of the 72 cases diagnosed with DLBCL were submitted to the CHOP (cyclophosphamide, doxorubicin hydrocloryde, vincristine sulfate, prednisone) regimen, 11 were submitted to a combination of $\mathrm{CHOP}$ with rituximab (R-CHOP) and 14 required other therapeutic regimens. As for clinical outcomes in the DLBCL group, 30 of the 72 cases (41.7\%) resulted in death about 13 months after diagnosis $(\mathrm{SD}=13.99)$.

The three cases of DHL (Table 2) were two women and a man, all over 60 years old, who presented no comorbidities. One of this group was previously diagnosed as $\mathrm{BL}$; the others, as DLBCL. None of them received a B-CLU/DLBCL/LB diagnosis. Clinically, the initial presentation in two patients was extranodal mass. B symptoms and enlarged lymph nodes were described in one patient. Neoplastic infiltration was not detected in the bone marrow or CNS in all three patients. None of these cases presented Ann-Arbor stage III or IV. The clinical course of the DHL patients was death in one, five and six months, regardless of chemotherapy. One individual was prescribed the R-CHOP regimen and another, the RHIPERCVAD regimen (cyclophosphamide, vincristine, doxorubicin and dexamethasone). The patient that died in less than 30 days did not start chemotherapy. 
Table 1 Sociodemographic. clinical. morphological. immunohistochemical and cytogenetic data of the diagnostic groups after FISH

\begin{tabular}{|c|c|c|c|c|c|c|}
\hline & \multicolumn{6}{|c|}{ Diagnostic Groups after FISH } \\
\hline & \multicolumn{2}{|c|}{$\mathrm{BL}(n=15)$} & \multicolumn{2}{|c|}{$\mathrm{DHL}(n=3)$} & \multicolumn{2}{|c|}{$\mathrm{DLBCL}(n=72)$} \\
\hline & $n$ & $\%$ & $\mathrm{n}$ & $\%$ & $n$ & $\%$ \\
\hline \multicolumn{7}{|l|}{ Sociodemographic data } \\
\hline Woman & 6 & 40 & 2 & 66.7 & 29 & 40.3 \\
\hline Man & 9 & 60 & 1 & 33.3 & 43 & 59.7 \\
\hline Age over 60 years old & 0 & 0 & 3 & 100 & 34 & 47.2 \\
\hline HIV & 1 & 6.7 & 0 & 0 & 2 & 2.8 \\
\hline LNH history & 0 & 0 & 0 & 0 & 2 & 2.8 \\
\hline Viral hepatitis & 0 & 0 & 0 & 0 & 4 & 5.5 \\
\hline \multicolumn{7}{|l|}{ Morphology } \\
\hline Monomorphic & 15 & 100 & 3 & 100 & 51 & 70.8 \\
\hline Polymorphic & 0 & 0 & 0 & 0 & 21 & 29.1 \\
\hline "Starry sky" pattern & 14 & 93.3 & 0 & 0 & 17 & 23.6 \\
\hline Diffuse growth & 15 & 100 & 3 & 100 & 71 & 98.6 \\
\hline Necrosis & 1 & 6.7 & 1 & 33.3 & 26 & 36.1 \\
\hline Mitotic activity & 12 & 80 & 1 & 33.3 & 52 & 72.2 \\
\hline Apoptosis & 14 & 93.3 & 3 & 100 & 57 & 79.1 \\
\hline Vesicular nuclear pattern & 4 & 26.7 & 1 & 33.3 & 52 & 72.2 \\
\hline Evident nucleolus & 5 & 33.3 & 0 & 0 & 64 & 88.8 \\
\hline Lobed nucleous & 2 & 13.3 & 0 & 0 & 30 & 41.6 \\
\hline Dense chromatin & 10 & 66.7 & 3 & 100 & 18 & 25 \\
\hline Loose chromatin & 6 & 40 & 0 & 0 & 54 & 75 \\
\hline Endothelial proliferation & 4 & 26.7 & 1 & 33.3 & 35 & 48.6 \\
\hline Cytoplasmic eosinophilia & 7 & 46.7 & 3 & 100 & 43 & 59.7 \\
\hline Soft tissue infiltration & 4 & 26.7 & 1 & 33.3 & 38 & 52.7 \\
\hline Stromal sclerosis & 0 & 0 & 0 & 0 & 19 & 26.3 \\
\hline \multicolumn{7}{|l|}{ Immunohistochemistry } \\
\hline CD20 & 15 & 100 & 3 & 100 & $68 / 70$ & 97.1 \\
\hline CD79a & 14 & 93.3 & 2 & 66.7 & $66 / 70$ & 94.3 \\
\hline PAX5 & 11 & 73.3 & 1 & 33.3 & $49 / 70$ & 70 \\
\hline CD10 & 15 & 100 & 3 & 100 & $31 / 71$ & 43.6 \\
\hline Bcl6 & 7 & 46.7 & 2 & 100 & $22 / 70$ & 31.4 \\
\hline $\mathrm{BCl} 2$ & 0 & 0 & 2 & 100 & $29 / 71$ & 40.8 \\
\hline MUM1 & 0 & 0 & 0 & 0 & $37 / 71$ & 52.1 \\
\hline TDT & 0 & 0 & 0 & 0 & 0 & 0 \\
\hline Myc & 5 & 33.3 & 0 & 0 & $11 / 70$ & 15.7 \\
\hline $\mathrm{Ki}-67>90 \%$ & 3 & 20 & 2 & 66.7 & $9 / 70$ & 12.8 \\
\hline \multicolumn{7}{|l|}{ Cytogenetic } \\
\hline MYC & 15 & 100 & 3 & 100 & 3 & 4.2 \\
\hline$B C L 2$ & 0 & 0 & 2 & 66.7 & 11 & 15.3 \\
\hline$B C L 6$ & 0 & 0 & 1 & 33.3 & 9 & 12.5 \\
\hline \multicolumn{7}{|l|}{ Prognostic markers } \\
\hline High levels of LDH & $5 / 6$ & 83.3 & 2 & 66.7 & $37 / 47$ & 78.7 \\
\hline Staging III/IV & 9 & 60 & 0 & 0 & $29 / 71$ & 40.8 \\
\hline
\end{tabular}


Table 1 Sociodemographic. clinical. morphological. immunohistochemical and cytogenetic data of the diagnostic groups after FISH (Continued)

\begin{tabular}{|c|c|c|c|c|c|c|}
\hline Bone marrow infiltration & 2 & 13.3 & 0 & 0 & $12 / 71$ & 16.9 \\
\hline CNS infiltration & 1 & 6.7 & 0 & 0 & $4 / 71$ & 5.6 \\
\hline B symptoms & 9 & 60 & 1 & 33.3 & $31 / 71$ & 43.6 \\
\hline Extranodal involvement & 8 & 53.3 & 2 & 66.7 & $35 / 71$ & 49.3 \\
\hline Nodal involvement & 8 & 53.3 & 1 & 33.3 & $44 / 71$ & 61.9 \\
\hline \multicolumn{7}{|l|}{ Therapeutic data } \\
\hline Chemotherapy & 11 & 73.3 & 2 & 66.7 & $65 / 71$ & 91.5 \\
\hline Chemotherapy and radiotherapy & 1 & 6.6 & 0 & 0 & 17 & 26.6 \\
\hline Bone marrow transplant & 0 & 0 & 0 & 0 & 1 & 1.4 \\
\hline Death & 5 & 33.3 & 3 & 100 & $30 / 66$ & 45.4 \\
\hline Recurrence & 0 & 0 & 0 & 0 & $2 / 59$ & 3.4 \\
\hline
\end{tabular}

Table 2 Clinical, immunophenotypic and cytogenetic of the three patients with double-hit lymphomas (DHL)

\begin{tabular}{|c|c|c|c|}
\hline & Patient 1 & Patient 2 & Patient 3 \\
\hline Age & 65 year old & 72 year old & 64 year old \\
\hline Gender & Woman & man & woman \\
\hline Previous diagnosis & $B L$ & DLBCL & DLBCL \\
\hline \multicolumn{4}{|l|}{ Immunohistochemistry } \\
\hline CD20 & positive & positive & positive \\
\hline CD79a & negative & positive & positive \\
\hline PAX5 & positive & negative & positive \\
\hline CD10 & positive & positive & positive \\
\hline $\mathrm{BCl} 2$ & negative & positive & positive \\
\hline Bcl6 & positive & negative & positive \\
\hline Myc & negative & negative & negative \\
\hline MUM1 & negative & negative & negative \\
\hline TDT & negative & negative & negative \\
\hline Ki-67 & $>90 \%$ & $>90 \%$ & $<90 \%$ \\
\hline \multicolumn{4}{|l|}{ Cytogenetic } \\
\hline MYC & positive & positive & positive \\
\hline$B C L 2$ & negative & positive & positive \\
\hline$B C L 6$ & positive & negative & negative \\
\hline \multicolumn{4}{|l|}{ Clinical data } \\
\hline Staging & IA & IA & $\mathrm{IB}$ \\
\hline Levels of LDH & High & $N D^{*}$ & $N D^{*}$ \\
\hline Bone marrow infiltration & absent & absent & absent \\
\hline CNS infiltration & absent & absent & absent \\
\hline Extra nodal involvement & absent & presence & presence \\
\hline Nodal involvement & presence & absent & absent \\
\hline B symptoms & absent & absent & presence \\
\hline Treatment & HIPER-CVAD & Not treated & $\mathrm{R}-\mathrm{CHOP}$ \\
\hline Death & Yes & yes & Yes \\
\hline Interval to death & 5 months & 1 month & 6 months \\
\hline
\end{tabular}

*ND=not avaible

\section{Morphological aspects}

The monomorphic and diffuse pattern with a "starry sky" appearance was the main aspects of the BL group, as expected according to the literature. Among the DLBCL patients, the morphological pattern of diffuse growth was frequent (98.6\%), with a "starry sky" pattern in $23.6 \%$ of the cases studied.

In the DHL group, the typical morphology in our study was diffuse monomorphic pattern, eosinophilic cytoplasm and apoptotic elements. The "starry sky" pattern, sclerosis or nuclear lobulation were not observed in this group.

\section{Immunohistochemical aspects}

The B immunophenotype was confirmed in all cases of BL. Positivity for CD10 (100\%) and Bcl6 (46.7\%) were also observed.

In the DLBCL group, among 70 patients, 34 were $\mathrm{GCB}$ type and 36 were $\mathrm{ABC}$ type. For the $\mathrm{ABC}$ type patients, in the immunohistochemistry analysis, one was BCL6 positive, 20 were $\mathrm{Bcl} 2$ positive and two patients are positive for $\mathrm{Myc}$ and $\mathrm{Bcl} 2$.

The three DHL had a B immunophenotype. MUM1, TDT and MYC were negative in all three biopsies. One case was positive for both BCL6 and BCL2. Cell proliferation, measured by Ki-67, was higher than $90 \%$ in two cases.

\section{Molecular aspects}

Molecular cytogenetic by FISH showed that all 15 patients diagnosed as $\mathrm{BL}$ presented translocation involving the $M Y C$ gene. In this group, one of five patients over 18 years old tested positive for EBV on the $\mathrm{CISH}$ test.

In the DLBCL group, positivity for $M Y C, B C L 2$ and $B C L 6$ was determined in three (4.2\%), nine (12.5\%) and 11 cases $(15.3 \%)$, respectively. In these patients, a statistically significant association $(p=0.011)$ between the 
positivity for $M Y C$ translocation and the "starry sky" morphological pattern was noted. Concerning EBV status, the $\mathrm{CISH}$ revealed ten positive cases in the DLBCL group.

One of the three DHL patients presented translocation of the $M Y C$ gene simultaneously with the BCL6 gene translocation (Patient 1; Fig. 1) and the others presented translocation involving the $M Y C$ gene simultaneously with the BCL2 gene (Patients 2 and 3). In this series, there were no cases of triple-hit lymphoma. None of the three patients tested positive for the EBV infection on CISH test.

Correspondence between the cytogenetic findings and immunohistochemical profile for the entire set of cases is shown in Table 3. Immunohistochemical positivity for Myc was verified in 19 cases, eight (42.1\%) of which were also positive in the cytogenetic analysis $(p=0.036)$. For this marker, the immunohistochemical technique showed high specificity (85\%) and low sensitivity (38\%), with regular agreement at identifying the respective translocation (Kappa $=0.23[0.0,0.49]$ ). Regarding $\mathrm{Bcl} 2$, the most interesting aspect is the high NPV, which is $95 \%(p=0.001)$, with regular agreement (Kappa $=0.35$ [0.13;0.56]). Four (12.5\%) of the 32 cases positive for Bcl6 by immunohistochemistry showed positivity in FISH ( $p=0.724)$, indicating poor agreement between the two methods for this marker (Kappa $=0.04[0.00 ; 0.30]$ ). The findings related to $B C L 6$ gene were not statistically significant.
Evaluation of these associations considering only patients with DLBCL are shown in Table 4. In this group, nine cases $(31 \%, p=0.005)$ showed immunohistochemical and cytogenetic positivity for $B C L 2$, with a regular agreement $($ Kappa $=0.29[0.04 ; 0.54])$. Parameters, such as a cell proliferation rate above $90 \%$, an $A B C$ type, and immunohistochemical positivity for Myc, were not associated with the detection of MYC translocation by FISH.

\section{Discussion}

DHL are rare, aggressive neoplasms that account for less than $10 \%$ of B-cell lymphomas and about $4 \%$ of highgrade lymphomas $[4,12]$. This first Brazilian study found three cases of DHL, two with translocations involving $M Y C$ and $B C L 2$, and one with translocations involving $M Y C$ and BCL6. The combination that is most often reported is the double translocation involving the $M Y C$ gene and the $B C L 2$ gene $(62 \%)[4,20]$.

The most important clinical and prognostic factors of DHL patients are the advanced stage at diagnosis, the presence of extranodal masses, the bone marrow or CNS infiltration and the age of over 60 years old [4, 10, $12,16,21]$. The three patients identified in this study were elderly; however, they did not present high AnnArbour stages or bone marrow/CNS infiltration, though two of the patients exhibited extranodal masses.

Survival is lower in patients with DHL. In this study, all three patients with DHL died, an average of 4 months

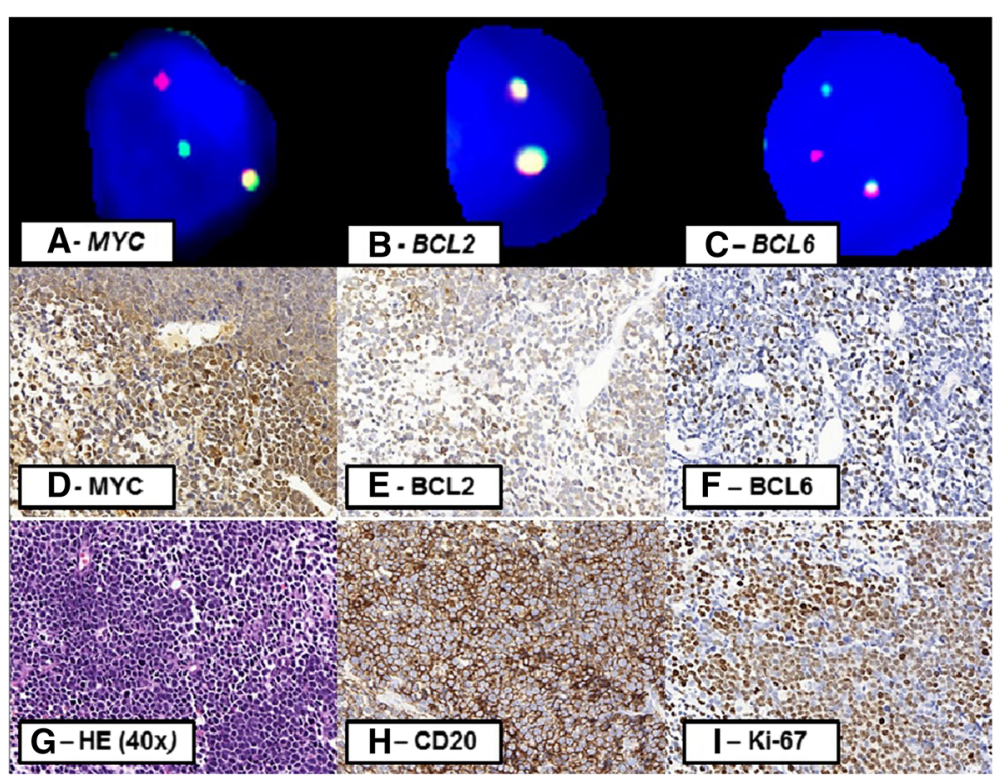

Fig. 1 Morphological, cytogenetic and immunohistochemical aspects of patient 1. Key: Images $\mathbf{a}$, b and $\mathbf{c}$ correspond to FISH: there is positivity for MYC (a) and BCL6 (c), in this case, the signals are indicated with arrows, and there is negativity for BCL2 (b). Images $\mathbf{d}$ (400x) and $\mathbf{e}$ (400x) exhibit the negativity for Bcl2 (below 70\% of marked cells) and Myc in immunohistochemistry (below 50\% of marked cells). In image f (400x), there is BCL6 positivity (above 50\% of marked cells). Image $\mathbf{g}$ (H\&E, 400x): the diffuse pattern in morphology. Positivity for CD20 confirms immunophenotype B and is shown in image $\mathbf{h}$ (400x). Image $\mathbf{i}(400 x)$ refers to cell proliferation rate above $90 \%$ 
Table 3 Immunohistochemistry (IHC) for Myc, Bcl2 and Bcl6 and cytogenetic (FISH) for MYC, BCL2 and BCL6, considering the total number of valid samples: sensitivity (S), specificity (E), positive predictive value (PPV) and negative predictive value (NPV), accuracy (A) and Kappa coefficient, with respective ranges of $95 \%$ confidence

\begin{tabular}{|c|c|c|c|c|c|c|c|c|c|}
\hline & $\mathrm{n}$ & $\mathrm{FISH}+$ & $p^{*}$ & $S$ & $E$ & PPV & NPV & A & Kappa \\
\hline \multicolumn{10}{|l|}{ MYC $(n=92)$} \\
\hline $\mathrm{IHC}$ negative & 73 & $13(18.0 \%)$ & 0.036 & 0.38 & 0.85 & 0.42 & 0.82 & $0.74[0.65 ; 0.83]$ & $0.23[0.0 ; 0.49]$ \\
\hline IHC positive & 19 & $8(42.1 \%)$ & & & & & & & \\
\hline \multicolumn{10}{|l|}{$\mathrm{BCL} 2(n=101)$} \\
\hline $\mathrm{IHC}$ negative & 64 & $3(4.6 \%)$ & 0.001 & 0.81 & 0.71 & 0.35 & 0.95 & $0.73[0.64 ; 0.81]$ & $0.35[0.13 ; 0.56]$ \\
\hline IHC positive & 37 & $13(35.1 \%)$ & & & & & & & \\
\hline \multicolumn{10}{|l|}{ BCL6 $(n=98)$} \\
\hline $\mathrm{IHC}$ negative & 66 & $6(9.0 \%)$ & 0.724 & 0.40 & 0.68 & 0.12 & 0.90 & $0.65[0.56 ; 0.75]$ & $0.04[0.0 ; 0.30]$ \\
\hline IHC positive & 32 & $4(12.5 \%)$ & & & & & & & \\
\hline
\end{tabular}

after diagnosis. According to the literature [16], the overall median survival rate is 8.2 months in this group of patients versus 56.8 months in patients with other high-grade lymphomas. Snurdel et al. (2010) [10] reported $70 \%$ of deaths within eight months in patients with DHL. The aggressiveness of DHL is possibly explained by the synergistic action of $M Y C$ and $B C L 2$ : proliferative activity with inhibition of apoptosis in the context of a complex karyotype [4, 20, 22, 23].

In this study, the best agreements between immunohistochemical and FISH results occurred with respect to the $M Y C$ gene and, mainly, the $B C L 2$ gene, with high NPV. Evaluations of the $M Y C$ gene and the BCL2 gene shows good results, however, there is a fair agreement by Kappa coefficient, indicating the need for caution in assessing the markers with the immunohistochemical method.

Immunohistochemical evaluation of $\mathrm{Myc}, \mathrm{Bcl} 2$ and Bcl6 is a problem discussed by several hematopathology groups [12, 22-24]. The cutoff for determining positivity for MYC varies between 30 and $50 \%$ in the literature, while for $\mathrm{Bcl} 2$, the variation is between 30 and $70 \%$ [22, 23, 27].

Perry et al. [24] studied the immunohistochemical expression of Myc and $\mathrm{Bcl} 2$ of 106 patients diagnosed with DLBCL, correlating their data with prognosis. Positivity for these markers, especially when both were positive, was related to worse prognosis, increasing the chances of death nine-fold. However, Perry et al. (2014) did not correlate their results with cytogenetic data [24].

Green et al. [25] studied the immunohistochemical and cytogenetic profiles of 193 patients diagnosed with DLBCL, of which $6 \%$ were DHL identified by FISH, and showed poor prognosis. Regarding immunohistochemistry, 29\% of patients were positive for $\mathrm{Myc}$ and $\mathrm{Bcl} 2$, and $54 \%$ of these patients had translocations involving one of these genes. These patients, regardless of the cytogenetic test results, showed worse survival rates compared with other patients [25].

Yan et al. [26] evaluated 336 patients with DLBCL by immunohistochemistry and FISH, and found a high specificity (approximately 90\%) of positivity for Myc and $\mathrm{Bcl} 2$ in the immunohistochemistry in relation to $\mathrm{FISH}$

Table 4 Immunohistochemistry (IHC) for Myc, BCl2 and BCl6 and cytogenetic (FISH) for MYC, BCL2 and BCL6, considering the group of DLBCL: sensitivity (S), specificity (E), positive predictive value (PPV) and negative predictive value (NPV), accuracy (A) and Kappa coefficient, with respective ranges of $95 \%$ confidence

\begin{tabular}{|c|c|c|c|c|c|c|c|c|c|}
\hline & $\mathrm{n}$ & $\mathrm{FISH}+$ & $p^{*}$ & $\mathrm{~S}$ & $E$ & PPV & NPV & A & Kappa \\
\hline \multicolumn{10}{|l|}{$\overline{M Y C}(n=70)$} \\
\hline $\mathrm{IHC}$ negative & 59 & $1(1.7 \%)$ & 0.062 & 0.67 & 0.87 & 0.18 & 0.98 & $0.86[0.78 ; 0.94]$ & $0.23[0.0 ; 0.67]$ \\
\hline $\mathrm{IHC}$ positive & 11 & $2(18.1 \%)$ & & & & & & & \\
\hline \multicolumn{10}{|l|}{$\operatorname{BCL} 2(n=71)$} \\
\hline $\mathrm{IHC}$ negative & 42 & $2(4.7 \%)$ & 0.005 & 0.81 & 0.66 & 0.31 & 0.95 & $0.69[0.58 ; 0.79]$ & $0.29[0.04 ; 0.54]$ \\
\hline IHC positive & 29 & $9(31 \%)$ & & & & & & & \\
\hline \multicolumn{10}{|l|}{$\mathrm{BCL6}(n=70)$} \\
\hline $\mathrm{IHC}$ negative & 48 & $6(12.5 \%)$ & 1.000 & 0.33 & 0.69 & 0.13 & 0.87 & $0.64[0.53 ; 0.76]$ & $0.01[0.0 ; 0.32]$ \\
\hline IHC positive & 22 & $3(13.6 \%)$ & & & & & & & \\
\hline
\end{tabular}


positivity for $M Y C$ and $B C L 2$ translocations, favoring its potential use for stratification in cases of DLBCL with aggressive behavior [26]. Kawamoto et al. [15] studied only DLBCL patients, by FISH and immunohistochemistry. They found that $M Y C$ translocation and $\mathrm{Bcl} 2$ immunohistochemical expression were independent prognostic factors and must be investigated at the initial diagnosis [15].

Kalaw et al. [28] studied the cell proliferation rate, measured by the percentage of staining for Ki67, as a potential selection parameter of patients for cytogenetic tests. The cutoff values used were $75 \%$ or $90 \%$ and both were not associated with detection of $M Y C$ translocations, as was seen in this study.

Mahmound et al. (2015) [27] studied the agreement in the evaluation of Myc expression by immunohistochemistry and noted great heterogeneity in the results, reflecting the subjective interference and the lack of a clear standard regarding the interpretation of this marker [27].

In this study, the "starry sky" morphological pattern, in the DLBCL context, positive immunohistochemistry for Myc in over $50 \%$ of cells, and positive immunohistochemistry for $\mathrm{Bcl} 2$ above $70 \%$ are indicated as potential selector parameters for patients eligible for cytogenetic study. However, further studies with larger case samples are required, for more detailed analysis of these associations, in special morphological pattern studies because it is a conventional and accessible method of evaluation in the pathology routine.

Swerdlow (2014) [23] emphasizes the importance of identifying cases of aggressive large B cell lymphomas, mainly due to the absence of a specific therapeutic protocol [23]. In this context, there is great interest in studies of agreement between immunohistochemical and cytogenetic results, mainly in relation to selector elements for molecular screening. In fact, difficulties related to the standardization of defining criteria of positivity for Myc and $\mathrm{Bcl} 2$ in immunohistochemical reactions has been reported.

\section{Conclusions}

This study presents the first Brazilian series of patients with double-hit lymphoma identified by cytogenetic study performed by FISH on 120 cases of high-grade lymphomas. For this study, high grade B-cell lymphomas, particularly when there is a "starry sky" pattern, must be submitted to immunohistochemistry for, at least, Myc andBcl2. When $\mathrm{Myc}$ and/or Bcl2 are positive, if it is possible, the investigation must continue with FISH test for $M Y C, B C L 2$ and $B C L 6$. These cases are high grade lymphomas and the molecular markers must be reported. In the situation that molecular approach is not possible, the immunohistochemistry results must be reported too, because they may represent a prognostic factor.

\section{Abbreviation}

ABC: $B$ cell activated or non-germinal centre; B-CLU/DLBCL/LB: B-cell lymphoma unclassifiable, with features intermediate between diffuse large B-cell lymphoma and Burkitt lymphoma; BL: Burkitt lymphoma; CISH for EBV: Chromogenic in situ hybridization (CISH) for EBV (Epstein Barr Virus); CNS: Central nervous system; DHL: Double-hit lymphomas; DLBCL: Diffuse large B-cell lymphoma; Fish: Fluorescence in situ hybridization; GCB: B germinal centre; HE: Hematoxylin and eosin; LDH: Lactic dehydrogenase; MO: Bone marrow infiltration; NHL: Non-Hodgkin lymphoma; THL: Triple-hit lymphomas; TMA: Tissue microarray platform

\section{Acknowledgement}

The authors thank the Department of Pathology from FMB-UNESP, AC Camargo Cancer Center and Amaral Carvalho Hospital.

\section{Funding}

The authors do not receive any financial support for this research.

\section{Availability of data and material}

Please contact author for data requests.

\section{Authors' contribution}

CCO is the main author and took part in all parts of the paper, since the initial idea until the final version of the paper. HMG, LK, LNM and EJH took part in the initial idea, reference discussion and clinical data collection and discussion. CCO, ADB, FCQ, IWC, FAS and PPR took part in the molecular study. MACD and CCO were responsible for the idea, project writing, studying the morphological and immunohistochemical aspects, final version of the paper. All authors approved this final version.

\section{Competing interests}

The authors declare that they have no competing interests.

\section{Consent for publication}

Not applicable.

\section{Ethics approval and consent to participate}

The study was approved by the Research Ethics Committee of FMB-UNESP, under protocol no. 4385-2012.

\section{Author details}

${ }^{1}$ Department of Pathology, Botucatu School of Medicine, São Paulo State University (FMB UNESP), Botucatu, São Paulo, Brazil. Botucatu School of Medicine, São Paulo State University (FMB UNESP), Botucatu, São Paulo, Brazil. ${ }^{3}$ Department of Pathology, AC Camargo Cancer Center, São Paulo, Brazil. ${ }^{4}$ Department of Pathology, Amaral Carvalho Hospital, Jaú, São Paulo, Brazil. ${ }^{5}$ Department of Internal Medicine, Botucatu School of Medicine, São Paulo State University (FMB UNESP), Botucatu, São Paulo, Brazil. ${ }^{6}$ Departamento de Patologia, Faculdade de Medicina de Botucatu (FMB), Universidade Estadual Paulista (UNESP), Distrito de Rubião Junior, s/ $\mathrm{n}^{\circ}$, Botucatu, SP Zip code: 18618-000, Brazil.

Received: 24 June 2016 Accepted: 20 December 2016 Published online: 07 January 2017

\section{References}

1. Jaffe $E_{1}$ Harris NL, Stein H, Isaacson PG. Classification of lymphoid neoplasms: the microscope as a tool for disease discovery. Blood. 2008;112(12):4384-6.

2. Hasserjian RP, Ponz BO, Ott G, Elenitoba-Johnson SK, Leval L. Commentary on the WHO classification of tumors of lymphoid tissues (2008): "Gray zone" lymphomas overlapping with Burkitt lymphoma or classical Hodgkin lymphoma. J Hematop. 2009;2(2):89-95.

3. Harris NL, Campo E, Jaffe ES, et al. Introduction to the WHO classification of tumors of haematopoietic na lymphoid tissues. In: Swerdlow SH, Campo E, Harris NL, Jaffe ES, Pileri SA, Stein H, et al., editors. WHO Classification of Tumours of Haematopoietic and lymphoid tussues, vol. 2. Lyon: IARC; 2008. p. $14-5$.

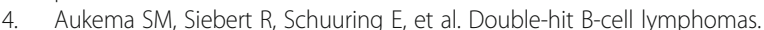
Blood. 2011;17(8):2319-3 
5. Salaverria I, Siebert R. The gray zone between Burkitt's lymphoma and diffuse large B-cell lymphoma from a genetics perspective. J Clin Oncol. 2011;29(14):1835-43.

6. Zhao XF. Pitfalls in diagnostic hematopathology: part II. Int J Clin Exp Pathol. 2009;3(1):39-46.

7. Zhang B, Calado DP, Pasqualucci L, Rajewsky K. An oncogenic role for alteranative NF-K $\beta$ signaling in DLBCL revealed upon deregulated BCL6 expression. Cell Rep. 2015;11:715-26.

8. Tanaka H, Hashimoto S, Abe D, Sakai S, Takagi T. Double-hit Lymphoma at second relapse of Burkitt-Ike Lymphoma: a case report. J Clin Exp Hematop. 2011;51(1):43-7.

9. Kluin PM, Harris NL, Stein H, Leoncini L, Raphäel M, Campo E, et al. B-cell lymphoma, unclassificable, with features intermediate between diffuse large B-cell lymphoma and Burkitt lymphoma. In: Swerdlow SH, Campo E, Harris NL, Jaffe ES, Pileri SA, Stein H, et al., editors. WHO classification of tumours of haematopoietic and lymphoid tussues, vol. 2. 4th ed. Lyon: IARC; 2008. p. 265.

10. Snuderl M, Kolman OK, Chen YB, et al. B-cell lymphomas with concurrent $\mathrm{IGH}-\mathrm{BCL} 2$ and MYC rearrangements are aggressive neoplasms with clinical and pathologic features distinct from Burkitt lymphoma and diffuse large B-cell lymphoma. Am J Surg Pathol. 2010:34(3):327-40.

11. Kramer MH, Hermans J, Wijburg E, et al. Clinical relevance of BCL2, BCL6, and MYC rearrangements in diffuse large B-cell lymphoma. Blood. 1998; 92(9):3151-62.

12. Li S, Lin P, Young KH, Kanagal-Shamanna R, Yin CC, Medeiros LJ. MYC/BCL2 Double-Hit high-grade B-cell lymphoma. Adv Anat Pathol. 2013;20:315-26.

13. Swerdlow SH, Campo E, Pileri SA, et al. The 2016 revision of the World Health Organization classification of lymphoid neoplasms. Blood. 2016 127(20):2375-90.

14. Smith SM, Anastasi J, Cohen KS, Godley LA. The impact of MYC expression in lymphoma biology: beyond Burkitt lymphoma. Blood Cells Mol Dis. 2010; 45(4):317-23.

15. Kawamoto K, Miyoshi H, Yoshida N, Nakamura N, Oshima K, Sone H, et al. MYC translocation and/or BCL2 protein expression are associated with poor prognosis in diffuse large B-cell lymphoma. Cancer Sci. 2016;107:853-61.

16. Landsburg DJ, Nasta SD, Svoboda J, Morrissette JJD, Schuster SJ. Double-hit cytogenetic status may not be predicted by baseline clinicopathological characteristics and is highly associated with overall survival in B cell lymphoma patients. Br J Hematol. 2014;166:169-74.

17. Friedberg WJ. Double Hit diffuse large B-cell lymphoma. J Clin Oncol. 2012; 30(28):3439-43.

18. Zhang XM, Aguillera N. New immunohistochemistry for B-cell lymphoma and Hodgkin lymphoma. Arch Pathol Lab Med. 2014;138(12):1666-72.

19. Ventura RA, Martin-Subero JI, Jone M, et al. FISH analysis for the detection of lymphoma-associated chromosomal abdnormalities in routine paraffinembedded tissue. JMD. 2006;8(2):141-51.

20. Aukema SM, Kreuz M, Kohler CW, et al. Biological characterization of adult MYC-translocation-positive mature B-cell lymphomas other than molecular Burkitt lymphoma. Haematologica. 2014;99(4):726-35.

21. Oki $Y$, Noorani M, Lin $P$, et al. Double-hit lymphoma: the MD Anderson Cancer Center clinical experience. Br J Hematol. 2014;166:891-901.

22. Swerdlow SH. Update on the WHO classification of malignant lymphomas. Pathology. 2014;46(S2):06.

23. Swerdlow SH. Diagnosis of 'double-hit' diffuse large B-cell lymphoma and B-cell lymphoma, unclassifiable, with features intermediate between DLBCL and Burkitt lymphoma: when and how, FISH versus IHC. Hematology Am Soc Hematol Educ Program. 2014;5(1):90-9.

24. Perry AM, Alvarado-Bernal Y, Laurini JA, et al. MYC and BCL2 protein expression predicts survival in patients with diffuse large B-cell lymphoma treated with rituximab. Br J Hematol. 2014;165:382-91.

25. Green TM, Young KH, Visco C, et al. Immunohistochemical double-hit score is a strong predictor of outcome in patients with diffuse large B-cell lymphoma treated with rituximab plus cyclophosphamide, doxorubicin, vincristine and prednisone. J Clin Oncol. 2012;30:3460-67.

26. Yan L-X, Liu Y-H, Luo D-L, et al. MYC expression in concert with BCL2 and BCL6 expression predictis outcome in Chinese patients with diffuse large B-cell lymphoma, not otherwise specified. PLoS One. 2014;9(8):e104068.
27. Mahmound AZ, George Tl, Czuchlewski DR, et al. Scoring of MYC protein expression in diffuse large B-cell lymphomas: concordance rate among hematopathologistis. Mod Pathol. 2015;28(4):545-51.

28. Mation-Kalaw E, Tan LHC, Tay K, et al. Does the proliferation fraction help identify mature B cell lymphomas with double- and triple-hit translocations? Histopathology. 2012;61:1214-18.

\section{Submit your next manuscript to BioMed Central and we will help you at every step:}

- We accept pre-submission inquiries

- Our selector tool helps you to find the most relevant journal

- We provide round the clock customer support

- Convenient online submission

- Thorough peer review

- Inclusion in PubMed and all major indexing services

- Maximum visibility for your research

Submit your manuscript at www.biomedcentral.com/submit
Biomed Central 